\title{
Classical conditioning and latent inhibition in the white rat'
}

CAROL CHACTO AND R. E. LUBOW

NORTH CAROLINA STATE UNIVERSITY

Two studies are reported. The first demonstrates classical conditioning of a tail movement in the rat. The second demonstrates latent inhibition.

Latent inhibition is defined as the effect of nonreinforced pre-exposure of the to-be-conditioned stimulus when such pre-exposure leads to a decrement in conditioning as compared to a control group which has had no such pre-exposure. Such an effect has been demonstrated in dogs (Konorski \& Szwejkowska, 1959), sheep and goats (Lubow \& Moore, 1959; Lubow, 1965), and rabbits (Markman \& Lubow, 1965). The effect also has been demonstrated, weakly, in adult humans (Perlmuter, 1966), in adolescents (Sokolov, 1963, pp. 247-249), and in children (Cantor \& Cantor, 1964).

One characteristic of those studies has been the large intersubject variability of the inhibitory effect, with some Ss exhibiting almost complete inhibition and others no inhibition. This large intersubject variance calls for rather large sample sizes. Unfortunately, animals commonly used in skeletal classical conditioning studies, and particularly in latent inhibition studies are, for the most part, cumbersome and uneconomical. The white rat would make an excellent subject, but a convenient conditioning methodology has been difficult to establish.

Early attempts to establish a classically conditioned skeletal response in the rat were unsuccessful (Schlosberg, 1934, 1936).

The purposes of the experiments which follow were: (1) to establish a methodology for classically conditioning tail movement in the rat, and (2) to apply this methodology to demonstrate latent inhibition in the rat. EXPERIMENT 1

\section{Method}

The Ss were 28 albino rats, 16 females and 12 males, 85 days old, of the Sprague-Dawley strain. The Ss were housed individually and had free access to food and water. The $S$ was restrained in a metal tube $2-1 / 2$ in. in diameter and 8 in. long. The S's tall was threaded through a hole in the center of a square metal plate which fitted into slots on the end of the tube. A cable clamp was fastened onto the base of the tail and the screw which tightened it fitted into a clamp soldered onto the plate. The $S$ was thus prevented from moving back and forth and from turning around in the apparatus. To restrict gross movements of the tall, the tip was held with a rubber-lined alligator clip attached to a rod and ring stand.

The CS was a $1 \mathrm{sec} 2500 \mathrm{cps}$ tone, $72 \mathrm{~dB}$ at $2 \mathrm{ft}$. The US was a $1.5 \mathrm{~mA}$ shock of $175 \mathrm{msec}$ delivered by a constant current shock source (LVE Model 1531). The US onset directly followed CS offset. The shock electrodes were small alligator clips on either side of the restraining clamp near the tip of S's tail.

A length of thread, attached to S's tail by a piece of Velcro, operated a myograph outside the experimental chamber. The myograph output was amplified and recorded by an $\mathbf{E}$ and $M$ Physiograph. A pen deflection of $1 \mathrm{~mm}$ or greater during the CS was counted as a CR.

The Ss were randomly assigned to one of three groups with at least four Ss of each sexper group. Group 1 received paired CS-US trials; Group 2 received only the CS; and Group 3 received unpaired $C S$ and US, with the US appearing once within each ITI, a minimum of $15 \mathrm{sec}$ after the first CS and 15 sec before the second CS. The ITI was randomized at 40,60 , and $80 \mathrm{sec}$.

Each $S$ received four days of acquisition and one day of extinction with 50 trials per day. The first trial on each day was preceded by a 15 min adaptation period in the apparatus.

\section{Results and Discussion}

The mean percentage of responses over the four days of acquisition and one day of extinction is shown in Fig. 1. The number of responses during acquisition was subjected to a treatment by days ANOVA. The treatment

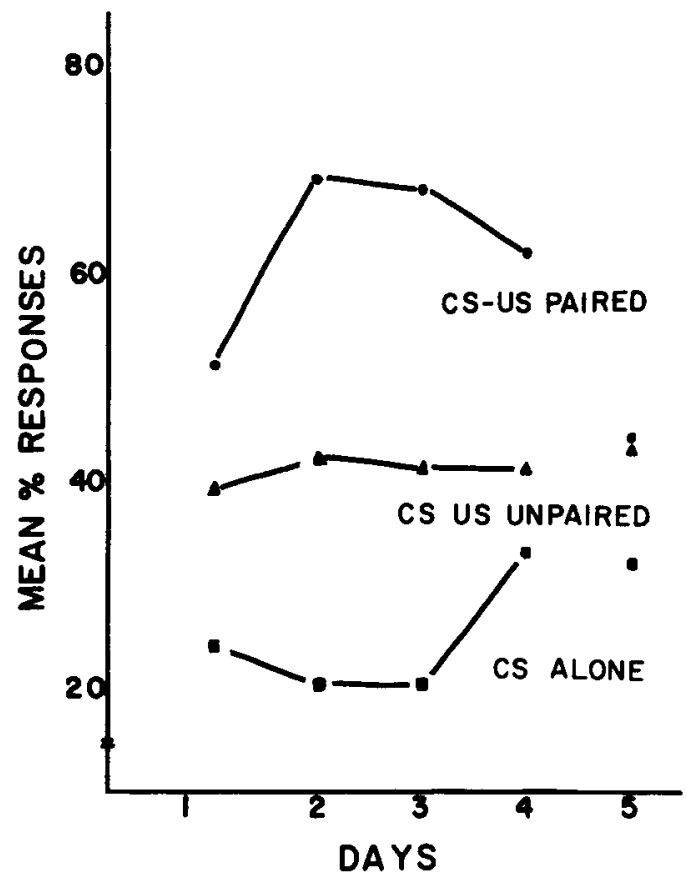

Fig. 1. Mean percentage of responses during four days of acquisition and one day of extinction. 
effect was significant ( $F=24.66, d f=2 / 24, p<.005)$. The days effect was marginal $(F=1.95$, df $=3 / 72, .05<p<$ $.10)$, while the treatment by days interaction was significant ( $F=2.46, d f=6 / 72, p<.05$ ). A $t$ test on the mean total number of responses of each group indicated that each mean differed from every other mean $(p<.005)$ in every case.

The extinction data were subjected to a separate treatment by blocks ANOVA. Neither the treatment nor blocks effect was significant.

The results indicate that a classically conditioned tail movement can be produced in the white rat. The highly significant treatment effect indicates that there are differences in number of responses among groups as would be expected if conditioning were occurring. The significant treatment by days interaction indicates that at least one treatment shows an effect over days. The nonsignificant days effect indicates that the other treatment(s) may tend to diminish this significance. Inspection of Fig. 1 shows quite clearly that this is the case. The CS-US paired group that is demonstrating conditioning exhibits an effect over days while the control groups exhibit no effect over days.

\section{EXPERIMENT 2}

\section{Method}

The Ss were 42 male albino rats, 75-115 days old. All were experimentally naive and housed six to a cage with free access to food and water. The apparatus was identical to that in the first experiment.

The Ss were randomly assigned to three groups of $14 \mathrm{Ss}$ each. Group A received 0 pre-exposures, Group B received 20 pre-exposures, and Group $C$ received 40 pre-exposures to the tone alone. The ITI was randomized at 40,60, and $80 \mathrm{sec}$. All Ss received 50 acquisition trials and 20 extinction trials. All Ss were given $15 \mathrm{~min}$ of adaptation to the apparatus before pre-exposure. To equalize the time spent in the apparatus by the different groups, Group A spent $40 \mathrm{~min}$ in the apparatus before acquisition; Group $B$ spent $20 \mathrm{~min}$ in the apparatus and then received 20 pre-exposures before acquisition; Group C received 40 pre-exposures followed immediately by acquisition.

Any discriminative deviation from the baseline which occurred during CS interval was recorded as a response.

\section{Results and Discussion}

The acquisition data were subjected to a treatment by blocks ANOVA. The treatment effect was highly significant ( $F=14.24$, df $=2 / 39, p<.005$ ), while the blocks effect was nonsignificant $(F=1.07, d f=4 / 156)$. The treatment by blocks interaction was sigmificant $(F=2.09, \mathrm{df}=8 / 156$, $\mathrm{p}<.05)$. Separate analyses indicated that Group $A$ was significantly different from both Groups $B$ and $C$, but that Groups $B$ and $C$ were not significantly different from each other. A $t$ test of the mean numbers of responses during extinction showed a significant difference $(t=2.09, d f=13, p<.05)$ between Group $A$ and Group B. Other comparisons yielded nonsignificant differences.

In summary then, the first experiment demonstrated a technique for classically conditioning a skeletal response in the rat. The second experiment extended the latent inhibition phenomenon to the rat, i.e., nonreinforced pre-exposure to the to-be-conditioned stimulus results in fewer conditioned responses as compared to a control group not pre-exposed. These findings with the rat should allow for further large sample size studies to determine both the parameters of the effect and its dependency on organismic variables.

References

CANTOR, G. N., \& CANTOR, J. H. Effects of conditioned stimulus familiarization on instrumental learning in children. $J$. exp. child Psychol, 1964, 1, 71-78.

KONORSKI, J., \& SZWEJKOWSKA, G. Chronic extinction and restoration of conditioned reflexes, IV. The dependence of the course of extinction and restoration of conditioned reflexes on the "history" of the conditioned stimulus (the principle of the primacy of first training). Acta Biol Exp., 1952, 16, 95-113.

LUBOW, R. E. Latent inhibition: Effects of non-reinforced pre-exposure of the CS. J. comp. physiol. Psychol., 1965, 60, 454-457.

LUBOW, R. E., \& MOORE, A. U. Latent inhibition: The effect of nonreinforced pre-exposure to the conditioned stimulus. J. comp. physiol. Psychol, 1959, 52, 415-419.

MARKMAN, R., \& LUBOW, R. E. Latent inhibition of the pinna responses of the albino rabbit as a function of time delay between preexposure and conditioning. Paper read at Psychonomic Society Meetings, Chicago, October, 1965.

PERLMUTER, L. C. Effect of CS manipulations on the conditioned eyelid response: Compounding, generalization, the inter-CS-interval, and pre-exposure. Psychon. Monogr. Suppl, 1966, 1, 271-286.

PROKASY, W. F. (Ed.) Classical conditioning: a symposium. New York: Appleton-Century-Crofts, 1965.

SCHLOSBERG, H. Conditioned response in the white rat. J. genet. Psychol, 1934, 45, 303-335.

SCHLOSBERG, H. Conditioned response in the white rat. II. Conditioned response based upon shock to the foreleg. J. genet. Psychol, $1936,49,107-138$.

SOKOLOV, Ye. N. Perception and the conditioned reflex. New York: Pergamon Press, 1963.

Note

1. This paper was prepared by the first author under NSF Undergraduate Research Participation supervised by the second author. The research was also supported in part by NIH Grants MH-12037-01 and K3-MH7189 to the second author. Portions of the paper were presented at the Southeastern Psychological Association Meetings, Atlanta, Georgia, April 15, 1967. 